\title{
Brotes epidémicos de Zika en Perú, ¿estamos en condiciones de controlarlo?
}

\section{Zika outbreaks in Peru, are we prepared to control them?}

Correspondencia Edward Chavez-Cruzado echavezc@scientiaceri.com

Recibido: 07/06/2016 Aprobado: 15/06/2016

Citar como: Chavez-Cruzado E Caballero-Alvarado J, GalvezOlortegui J. Brotes epidémicos de Zika en Perú, ¿estamos en condiciones de controlarlo?. Acta Med Peru. 2016;33(2):159-60
Edward Chavez-Cruzado ${ }^{1,2}$, Jose Caballero-Alvarado ${ }^{2,3}$, Jose GalvezOlortegui ${ }^{1,4}$

1 Unidad de Generadora de Evidencias y Vigilancia Epidemiológica, Scientia Clinical and Epidemiological Research Institute. Trujillo, Perú.

2 Escuela de Posgrado, Universidad Privada Antenor Orrego. Trujillo, Perú.

3 Hospital Regional Docente de Trujillo. Trujillo, Perú.

4 Facultad de Medicina, Universidad Nacional de Trujillo. Trujillo, Perú.

El virus Zika ha generado un alto impacto a nivel mundial, con un incremento de la prevalencia en Latinoamérica en los últimos dos años trasmitiéndose principalmente por la picadura del mosquito Aedes Aegypti (vector de los virus Dengue y Chikunguya) [1]. Recientemente se han descrito otras vías de transmisión (transfusiones sanguíneas y relaciones sexuales) que acompañan la presencia actual de cinco haplotipos en nuestro país [1].

En el mundo, al 30 de junio del 2016, 61 países han presentado reporte de infección por Zika, de los cuales 14 presentaron transmisión entre el 2007 y 2014, y 47 tuvieron su primer brote desde el 2015; del mismo modo se reportaron 1667 casos de microcefalia en 13 países ( $96,9 \%$ de casos en Brasil), síndrome de Guillain Barré en 13 países, y 10 casos de transmisión no vectorial en 10 países [2]. En América, 40 países reportaron casos entre el 2015 y 2016 [2] y en Perú se reportaron 14 casos importados y 79 casos autóctonos, en distintas ciudades: 63 en Jaén (31 gestantes), 7 en Yurimaguas (01 gestante), 4 en tumbes, 2 en Tocache, 1 en Iquitos, 1 en Pucallpa y 1 en Lima (trasmisión sexual) [3], existiendo un potencial riesgo de brotes epidémicos si consideramos que 385 distritos de 20 departamentos a nivel nacional, presentan al vector trasmisor y cuentan con condiciones adecuadas para una rápida diseminación de la infección (Tabla 1) y muchos de ellos han presentado brotes de dengue, con un gran número de casos en el norte del país.

Como medida de preparación ante la introducción del Zika, la Dirección General de Epidemiologia en el Perú (DGE), publicó el presente año el plan nacional de preparación y respuesta frente a la enfermedad por virus Zika [4]. Sin embargo, la situación actual en Jaen evidencia un brote epidemico en su fase inicial, con 348280 pobladores y 9291 gestantes esperadas para el presente año, en riesgo de contagio de Zika. Actualmente el sector salud ha iniciado la vigilancia de casos, incluyendo especialmente a mujeres gestantes (7 casos con infección en el primer trimestre de gestación), y activacion del protocolo sanitario de urgencia: vigilancia centinela de microcefalia, síndrome de Guillain-Barre y el Comité Operativo de Emergencias Nacional de Salud para prevenir y controlar el Zika [3]. 
Tabla 1. Población susceptible que habita áreas de riesgo, infestadas por Aedes aegypti, y casos autóctonos de Zika, por departamentos - Perú.

\begin{tabular}{|c|c|c|c|c|}
\hline Departamentos & $\begin{array}{c}\text { Casos Autóctonos } \\
\text { de Zika }\end{array}$ & $\begin{array}{c}\text { Distritos infestados } \\
\text { por Aedes aegypti }\end{array}$ & $\begin{array}{c}\text { Población susceptible } \\
\text { en riesgo }\end{array}$ & $\%$ \\
\hline Lima & 1 & 40 & 8463148 & 45,9 \\
\hline Piura & 0 & 39 & 1623399 & 8,8 \\
\hline La Libertad & 0 & 19 & 1195714 & 6,5 \\
\hline Callao & 0 & 4 & 912273 & 5,0 \\
\hline Loreto & 8 & 26 & 854309 & 4,6 \\
\hline San Martín & 2 & 74 & 824027 & 4,5 \\
\hline Lambayeque & 0 & 18 & $78715^{8}$ & 4,3 \\
\hline Ica & 0 & 23 & 643085 & 3,5 \\
\hline Ancash & 0 & 8 & 472645 & 2,6 \\
\hline Junín & 0 & 14 & 464881 & 2,5 \\
\hline Ucayali & 1 & 11 & 463080 & 2,5 \\
\hline Huánuco & 0 & 20 & 402830 & 2,2 \\
\hline Cajamarca & 63 & 27 & 395947 & 2,2 \\
\hline Tumbes & 4 & 13 & 234638 & 1,3 \\
\hline Amazonas & 0 & 14 & 222851 & 1,2 \\
\hline Cusco & 0 & 13 & 187667 & 1,0 \\
\hline Madre de Dios & 0 & 10 & 132598 & 0,7 \\
\hline Pasco & 0 & 5 & 82791 & 0,5 \\
\hline Ayacucho & 0 & 5 & 55800 & 0,3 \\
\hline Puno & 0 & 2 & 15756 & 0,1 \\
\hline Total & 79 & 385 & 18434597 & 100 \\
\hline
\end{tabular}

Adaptado de: Ministerio de Salud [3] y Plan nacional de preparación y respuesta frente a la enfermedad por el virus Zika - Perú [4].

Los reportes de tasas de ataque en El Salvador(>250/105) y Colombia(>150/105) y la prevalencia de microcefalia de hasta 20 veces más en Brasil [5], asociado a las dificultades para controlar el vector trasmisor y condiciones de salubridad, hacen más vulnerables a nuestro pais. En la última semana epidemiológica no se han confirmado nuevos casos en el país y esto podría deberse al cambio de estacion a invierno y al fenómeno de La Niña. Ante esta realidad, ¿es posible que el plan establecido sea efectivo en el control del Zika?, ergo el Ministerio de Salud afronta la emergencia sanitaria esperando un control oportuno, evitando el incremento de nuevos casos y su diseminación a otras regiones con mayor población en riesgo.

Finalmente es necesario que la Estrategia Sanitaria Nacional de Enfermedades Metaxénicas, tome acciones más agresivas en el control vectorial, búsqueda activa de casos y vigilancia centinela de microcefalia y síndrome de Guillain Barre asociados a virus Zika a fin de disminuir el impacto de la epidemia de Zika en Perú.

\section{Fuente de financiamiento:}

Los autores declaran no haber recibido ninguna financiación para la realización de este trabajo.

\section{Declaración de conflicto de intereses:}

Los autores declaran no tener conflicto de intereses con la publicación de este artículo.

\section{REFERENCIAS BIBLIOGRÁFICAS}

1. Maguiña C, Galán-Rodas E. El virus Zika : una revisión de literatura. Acta Med Peru. 2016;33(1):35-41.

2. World Health Organization (WHO). Zika situation report: Zika Virus, Microcephaly, and Guillain-Barré syndrome - 9 June 2016 [Internet]. Genova: WHO; 2016 [citado el 02 de julio del 2016]. Disponible en: http://www.who.int/emergencies/zika-virus/ situation-report/30-june-2016/en/

3. Perú, Ministerio de Salud. Minsa activa el Comité Operativo de Emergencia Nacional de Salud para Prevención y Control de Zika [Internet]. Lima: MINSA. [citado el o2 de julio del 2016]. Disponible en: http://www. minsa.gob.pe/?op $=51 \&$ nota $=18577$

4. Perú, Ministerio de Salud. Plan nacional de preparación y respuesta frente a la enfermedad por el virus Zika. Lima: MINSA; 2016.

5. Pan American Health Organization (PAHO). Zika-Epidemiologial Update - 17 March 2016 [Internet]. Washington, D.C.: PAHO; 2016 [citado el 13 de junio del 2016]. Disponible en: http://www. paho.org/hq/index.php?option=com_docman\&task=doc_ view $\&$ Itemid $=270 \&$ gid $=33768 \&$ lang $=e n$ 